\title{
El principio de deferencia razonada y las actuaciones de las Cámaras durante la tramitación de la ley. Examen de una sentencia del Tribunal Constitucional ${ }^{*}$ The principle of reasoned deference and Chambers actions during the pendency of the law. Review of a decision of the Constitutional Court
}

*Abogado, profesora de Derecho Constitucional, Universidad Católica de Chile. Magister (c) en Derecho Constitucional, Universidad Católica de Chile. Co-autora, con don Alejandro Silva Bascuñán, del Tratado de Derecho Constitucional (Editorial Juridica de Chile, 13 tomos publicados.

${ }^{* *}$ Artículo recibido el 8 de agosto de $2014 \mathrm{y}$ aceptado para su publicación el 8 de septiembre de 2014.

\section{Resumen}

El presente artículo desarrolla uno de los principios basales de los modernos estados constitucionales de derecho, a través de una sentencia de nuestro Tribunal Constitucional: el principio de deferencia razonada. Dicho principio se articula a partir de diversas claves de bóveda tales como la autonomía del legislador, la legitimidad del parlamento, la separación de funciones públicas y las reglas constitucionales que regulan el proceso legislativo, todas las cuales se manifiestan como expresión del citado principio, al cual deben sujetarse los órganos encargados de controlar la constitucionalidad de la ley.

\section{Palabras clave}

Principio de deferencia razonada - separación de funciones - Parlamento - Tribunal Constitucional.

\section{Abstract \\ This article is dedicated to develop one of the basal principles of modern constitutional Rule of Law, through a judgment of our Constitutional Court: the principle of reasoned deference. This principle is articulated from various keystones such as the autonomy of the legislature, the legitimacy of parliament, the separation of public service and constitutional rules that govern the legislative process, all of which are manifested as}


an expression of this principle and to which should be subject the bodies responsible for monitoring the constitutionality of the law.

\section{Keywords}

Reasoned deference principle - separation of functions - Parliament - Constitutional Court.

\section{Introducción}

1.- El Parlamento posee ciertas características que lo llevan a gozar de una autonomía que los órganos encargados de controlar la constitucionalidad de la ley no pueden sino reconocer y respetar por aplicación del principio de "deferencia razonada". Si goza de discrecionalidad para determinar tanto el contenido como la oportunidad de la ley, ello también se extiende a diversas actuaciones que puede realizar durante la formación de la ley.

Nos interesa examinar aquí la sentencia del Tribunal Constitucional, rol No 2646, de 22 de abril de 2014, recaída en el requerimiento de inconstitucionalidad presentado en contra de la actuación del Presidente de la Cámara de Diputados, producida durante la tramitación del proyecto de ley que permite la introducción de la Televisión Digital Terrestre y que consistió en la declaración de inadmisibilidad de 11 de las 28 observaciones que el Presidente Sebastián Piñera formulara al referido proyecto. Como el mencionado fallo incide en una actuación de la Cámara producida durante la tramitación de un proyecto de ley, antes de examinar su contenido, creo necesario primero analizar la naturaleza que posee una facultad de esa índole.

\section{La soberanía del Parlamento}

2.- Partamos recordando que si bien en Inglaterra es donde se establecieron las bases del modelo de Parlamento moderno que hoy conocemos, fue como consecuencia de las ideas fundantes del liberalismo filosófico que llevaron a la Revolución Francesa que a dicha institución se le atribuyó una especial preponderancia sobre los demás órganos públicos, por constituir sus miembros representantes directos de la voluntad general, siendo su tarea primordial elaborar la ley, la cual fija límites a la actuación de todos los poderes. Se buscaba de este modo combatir al absolutismo monárquico entregando la soberanía al pueblo -según Rousseau- o a la Nación -según Sieyes y Mirabeau-, pero con las mismas cualidades que al poder absoluto e ilimitado de los reyes se solía atribuir, al vincular la fuerza de la ley a la de un poder legislativo capaz de adoptar decisiones 
soberanas en nombre de una función ordenadora general ${ }^{1}$. Se impone así el gobierno de las leyes y no el de los hombres, como una forma de combatir el despotismo monárquico, configurándose las bases de un Estado Liberal de Derecho, que se afirma a través del principio de legalidad. ${ }^{2}$

Otro principio rector del Estado decimonónico es el de separación de los poderes, conforme al cual, para evitar abusos y en resguardo de las libertades ciudadanas, las funciones públicas deben ser ejercidas por diferentes órganos que actúan en forma independiente entre sí. Consecuentemente, el Parlamento posee un carácter autónomo y no depende de ningún otro ente estatal para producir, derogar y modificar las normas legales.

No puede olvidarse, sin embargo, que el Estado Liberal establece las bases del fenómeno del "constitucionalismo", como tendencia a plasmar en textos escritos y solemnes las bases fundamentales de la organización del poder y el reconocimiento de los derechos individuales. A la Constitución -que nace como consecuencia del pacto social que celebran los hombres según las teorías contractualistas- se le comienza a atribuir carácter supremo, por ser la regla que da validez al resto de las normas jurídicas, todas las cuales se hallan subordinadas a ella. Entonces, si la Carta Fundamental está en la cúspide de la jerarquía normativa -como ya lo afirmó expresamente en 1803 el derecho norteamericano en el célebre fallo Marbury con Madison-, la libertad de determinación del legislador debe encontrar su límite en tal preceptiva, por lo que la ley que formal o sustantivamente vulnere sus reglas debe declararse inválida mediante los diferentes mecanismos de control de su constitucionalidad que se establezcan.

3.- El valor del Parlamento resulta además consecuencia de la innegable legitimidad tanto de origen como de ejercicio de que gozan sus integrantes dentro de la democracia. El Parlamento constituye, como sostiene Peter Häberle, el "principal órgano legitimado democráticamente de manera directa. Incluso en una democracia le corresponde una especial legitimación, ya que representa la diversidad del pueblo dividido pluralistamente y en cierto modo es un 'espejo', un foro amplio de la Nación”’ ${ }^{3}$. Actúa entonces como genuino exponente de la voluntad del pueblo no sólo porque a éste corresponde dar origen al título de los parlamentarios, sino porque dicha representación se manifiesta materialmente a través de la legitimidad de ejercicio en la función, lo que los obliga a actuar conforme a los intereses ciudadanos, de manera tal que el pueblo pueda reconocerse en esa acción al percibir que éstos gestionan los asuntos que les afectan como si fueran los suyos propios, con lo cual ganan su confianza ${ }^{4}$.

Por otra parte, sin perjuicio de las críticas que mereció la forma en que en un comienzo se había comprendido el concepto de "soberanía", por haberse formulado con las características de constituir un poder absoluto e ilimitado, actualmente el vocablo se sigue empleando para destacar algunas cualidades típicas y exclusivas del poder del

ZAGREBELSKY (2005), pp. 24 y 25.

Garrorena Morales (2011), pp. 51 y 52.

HÄBERLE (2007), p. 339

BöCKENFORDE (2000), pp. 145-146. 
Estado, como son su unidad, independencia, carácter supremo, autarquía, suficiencia, incluyendo también su facultad de auto determinarse, es decir, de establecer sus propias reglas y actuar conforme a ellas.

Como dice Heller, forma parte de la esencia misma del concepto de soberanía "la capacidad o facultad para positivizar las normas jurídicas de más alto rango de la comunidad" 5 . Entre dichas normas jurídicas tiene importancia trascendental la ley, la cual, como toda regla de derecho, constituye una decisión valorativa que el órgano legislativo adopta en nombre del pueblo porque es legitimada por él mismo. Por ello, como dice Herman Heller, "la ley piensa y quiere lo que el espíritu del pueblo, en su calidad de intérprete razonable, puede obtener de ella", aunque no puede olvidarse que "los parlamentos no crean las normas jurídicas fundamentales, sino que las toman como algo vivo, limitándose a transformarlas" 6 .

4.- Los integrantes del Parlamento deben desempeñar su cargo en aras del interés general, es decir, del bien común. Es esa la finalidad que mueve al Estado y explica su razón de ser, la que ha de inspirar la actividad del órgano encargado de formular la ley. Si desde un punto de vista abstracto, el "bien común" puede definirse del modo como lo hace la Constitución de $1980^{7}$, desde un punto de vista subjetivo, concreto o específico, comprende la idea de derecho que prevalece en una sociedad política en un momento determinado de su devenir histórico ${ }^{8}$. Esa idea que concita la mayoría en un medio social va variando en el tiempo, por lo que, como dice Häberle, el bien común subjetivo constituye "un concepto guía abierto al desarrollo".

Lo que venimos diciendo explica que el Parlamento, como principal órgano encargado de legislar - por cierto no el único, porque el Jefe de Estado participa asimismo en forma muy activa en la elaboración de la ley en su carácter de colegislador ${ }^{10}$-, goza de autonomía e independencia para actuar en la configuración del bien común subjetivo a través del proceso de formación de la ley. Tras esa finalidad, le corresponde innovar y actualizar el derecho objetivo para solucionar los diversos problemas sociales que se vayan presentando y representar las necesidades de cambio que el pueblo demanda, por cuanto recibe su título de éste y a él ha de rendir cuenta de su labor. Se trata entonces de una actividad esencialmente "política", desde que se relaciona con el gobierno del Estado y el interés general.

HeLler (1965), p. 141.

Heller (1965), ob. cit. p. 179.

Su artículo $1^{\circ}$, luego de disponer que el Estado está al servicio de la persona humana, reconoce que "su finalidad es promover el bien común -y por lo tanto todos sus órganos, entre ellos el Parlamento, están obligados a ello-, para lo cual debe contribuir a crear las condiciones sociales que permitan a todos y a cada uno de los integrantes de la comunidad nacional su mayor realización espiritual y material posible, con pleno respeto a los derechos y garantías que esta Constitución establece" (inc. $3^{\circ}$ ).

SiLVA BASCUÑán (1997), pp. 199-200.

HÄBERLE (2007), ob. cit., pp. 379 y 380.

10 Según la Constitución de 1980, el Presidente de la República concurre a la formación de las leyes (art. 32 $\mathrm{N}^{\mathrm{o}}$ 1), inicia proyectos de ley (art. 65 inc. $1^{\circ}$ ), gozando incluso de iniciativa exclusiva respecto de ciertas materias (arts. $63 \mathrm{~N}^{\circ} 14$ y 65 inc. $3^{\circ}$ y $4^{\circ}$ ); presenta indicaciones por medio de sus Ministros, quienes concurren a las sesiones de las Cámaras tomando parte en el debate de los proyectos (art. 37 inc. $1^{\circ}$ ) y hace presente y califica la urgencia en el despacho de un proyecto (art. 74). Además, en su calidad de Jefe de Estado, el Presidente de la República sanciona o veta la ley y, actuando como Ejecutivo, la promulga y publica. 


\section{El principio de deferencia razonada}

5.- Como consecuencia tanto del principio de separación de funciones como de la esfera de autonomía que ha de reconocerse al legislador, los órganos jurisdiccionales encargados de controlar la constitucionalidad de la ley deben respetar el principio de "deferencia razonada", que consiste "en reconocer al órgano responsable de la producción de preceptos jurídicos la potestad de buscar de manera flexible las fórmulas normativas que, ajustadas a la Carta Fundamental, le parezcan necesarias o convenientes para la mejor consecución del bien común"11.

Por lo tanto, el legislador tiene libertad para elegir la regulación que considere más apropiada y ello no está sujeto a control jurisdiccional. Sólo si infringe los márgenes que contempla la Ley Fundamental, puede el Tribunal Constitucional intervenir para reparar el vicio de constitucionalidad que se haya producido, como consecuencia de haberse vulnerado el principio de legalidad o de juridicidad contemplado en el art. 7 de nuestra Carta Política.

Nuestro Tribunal Constitucional ha acogido el principio de deferencia razonada cuando ha dicho que "los actos legislativos, emanados de un órgano expresivo de la soberanía, concebido para dictar normas obligatorias de general aplicación, se encuentran dotados de un principio de legitimidad evidente; de suerte tal que su contrariedad con el contenido de la ley fundamental debe manifestarse clara y categóricamente y no cabe inferirla de simples contradicciones aparentes. En tal sentido, el intérprete constitucional orienta su tarea en la búsqueda de conciliar alguna interpretación racional de la norma legal que se compadezca con los valores, principios y normas de la Constitución" ${ }^{2}$. Refiriéndose a la esfera de autonomía del legislador, el propio tribunal ha expresado que "comprende, básicamente, el conjunto de apreciaciones de conveniencia y oportunidad política que lo llevan a la adopción de una u otra fórmula normativa"13, sin que le corresponda emitir un juicio de mérito sobre la ley, porque "si así no procediera se excedería en sus atribuciones transformándose en un órgano colegislador, lo que constituiría una grave infracción a la Constitución" ${ }^{14}$; ni tampoco cuestionar "la precisión, completitud y eficiencia de la ley", ya que ello "implica un juicio político y técnico que excede el control jurídico constitucional"; ni, en fin, sustituir "el juicio propio del legislador ni juzgar la sabiduría o mérito de los instrumentos que emplea" 15 .

De este modo, nuestra máxima magistratura constitucional reconoce que, como la Carta Fundamental no puede regular en forma completa todas las materias compren-

Zapata LARraín (2008), p. 229.

STC Rol N 549 , de 24 de julio de 2006.

STC Roles $\mathrm{N}^{\circ} 1219$, de 31 de enero de 2009 (cons. $10^{\circ}$ ) y $\mathrm{N}^{\circ} 1295$, de 6 de octubre de 2009 (cons. $28^{\circ}$ ). Veáse también, por ejemplo, roles $\mathrm{N}^{\circ}$ 664, de 23 de noviembre de 2006 (cons. 22), $\mathrm{N}^{\circ}$ 797, de 24 de enero de 2008; $\mathrm{N}^{0} 811$, de 31 de enero de 2008.

$14 \quad$ STC Rol No 43, de 24 de febrero de 1987. Véase también fallos rol No 67, de 12 de mayo de 1989; rol No 141, de 12 de febrero de 1992, y rol No 334, de 21 de agosto de 2001.

15 STC Rol No 1295, de 6 de octubre de 2009 (cons. 29). 
didas en su texto, el legislador -como órgano esencialmente político- ha de gozar de independencia para adoptar una u otra norma, siempre que lo haga actuando en forma racional, no arbitraria, dentro del margen de discrecionalidad que le fija la propia Constitución pero sin atropellarla.

6.- Si, desde un punto de vista sustantivo, el órgano legislativo es libre para determinar tanto el contenido como la oportunidad de la ley, desde un punto de vista formal el Parlamento también posee independencia para adoptar las decisiones que sean necesarias para ir avanzando en el debate, tramitación y aprobación de los proyectos que conozca, siempre actuando dentro de los límites que deriven del proceso legislativo establecido tanto en la Carta como en la ley ${ }^{16}$.

Como efecto de la aplicación del principio de autonomía parlamentaria, debido a su naturaleza de corporaciones de derecho público, en el derecho parlamentario a una y otra Cámara se les reconoce la facultad de dictar sus propios reglamentos internos, con el fin de regular su composición, organización y atribuciones ${ }^{17}$.

En nuestro ordenamiento jurídico, sin embargo, las materias más fundamentales relacionadas específicamente con los trámites de formación de la ley se reglamentan tanto en la propia Constitución como en la ley orgánica constitucional del Congreso Nacional No 18.918, en cumplimiento de lo ordenado por el inciso final del art. 55 de la Carta.

Entre dichas normas legales se encuentra aquella vinculada al fallo que luego examinaremos, referida a la facultad del Presidente de cada Cámara de declarar inadmisibles las observaciones que formule el Jefe de Estado a un proyecto de ley cuando éstas no tengan relación directa con las ideas matrices o fundamentales del mismo, regla contenida en el art. 32 de la ley orgánica constitucional del Congreso Nacional y relacionada, a su vez, con la prohibición establecida en el art. 73 inc. $2^{\circ}$ de la Constitución, según la cual en "ningún caso se admitirán las observaciones que no tengan relación directa con las ideas matrices o fundamentales del proyecto, a menos que hubieran sido consideradas en el mensaje respectivo".

Recordemos que a través del veto -o, como lo denomina la Carta, de las observaciones- el Presidente de la República manifiesta su desaprobación a un proyecto de ley aprobado por el Congreso en uno o más aspectos de su contenido. En nuestro sistema constitucional tales observaciones no tienen un efecto absoluto sino meramente suspensivo, porque ponen a las dos Cámaras en la necesidad de volver a examinar el proyecto en su integridad o en los puntos que el Jefe de Estado indique si el veto es parcial, de manera tal que si desechan algunas o todas las observaciones del Presidente se impondrá su proyecto por sobre el veto si insisten con los dos tercios de sus miembros presentes. ${ }^{18}$ Por otra parte, no olvidemos que las ideas matrices o fundamentales de un proyecto

16 Para Häberle, la actividad legislativa "puede concebirse como procesamiento permanente del cambio social en el tiempo y ofrece variedad de procedimientos y técnicas pertinentes”, HäBERLE (2007), ob. cit., p. 158.

Véase SiLVA G. (2013).

18 SiLVA Bascuñán (2000), pp. 180-201. 
de ley son "aquellas principales, básicas, de mayor repercusión, de las cuales derivan o pueden provenir las que son simple desarrollo, complemento, derivación o corolario de la fuerza generadora de las primeras" 19 .

El art. 32 de la referida ley orgánica dispone:

"Las observaciones o vetos que el Presidente de la República formule a un proyecto de ley o de reforma constitucional aprobado por el Congreso Nacional, sólo serán admitidas cuando tengan relación directa con las ideas matrices of fundamentales del mismo, a menos que las ideas contenidas en esas observaciones hubieren sido consideradas en el mensaje respectivo.

Corresponderá al presidente de la Cámara de origen la facultad de declarar la inadmisibilidad de tales observaciones cuando no cumplan con lo prescrito en el inciso anterior. El hecho de haberse estimado admisibles las observaciones en la Cámara de origen no obsta a la facultad del presidente de la Cámara revisora para declarar su inadmisibilidad.

En los dos casos previstos en el inciso anterior, la sala de la Cámara que corresponda podrá reconsiderar la declaración de inadmisibilidad efectuada por su presidente. La circunstancia de que no se haya declarado tal inadmisibilidad no obstará a la facultad de las comisiones para hacerla. Dicha declaración podrá ser revisada por la Sala.

La declaración de inadmisibilidad podrá hacerse en todo tiempo anterior al comienzo de la votación de la correspondiente observación".

7.- Entre las diferentes decisiones que pueden adoptar las Cámaras durante el debate de la ley, fundadas asimismo en la autonomía legislativa de que gozan, se encuentran los acuerdos políticos, mediante los cuales se respaldan o se rechazan proyectos, indicaciones, informes de comisión, vetos, etc., constituyendo compromisos para votar a favor o en contra de determinadas iniciativas.

El significado que damos en este caso al vocablo "acuerdo" se ajusta a los diferentes significados que el Diccionario de la Lengua Española entrega de ese término como "resolución que se toma en los tribunales, sociedades, comunidades u órganos colegiados", "resolución premeditada de una sola persona o de varias", "convenio entre dos o más partes" o "reflexión o madurez en la determinación de algo".

Respecto de este tipo de actuaciones de carácter procedimental, el órgano jurisdiccional encargado de ejercer el control de constitucionalidad de la ley ha de ajustarse al principio de deferencia razonada por cuanto no le corresponde calificar su mérito o conveniencia, siempre que, como ya dijimos, tal actuación se ajuste a la Carta Fun-

19 Silva Bascuñán (2000), ob. cit., p. 123. 
damental. Como veremos enseguida, acerca de este punto se pronuncia el fallo del Tribunal Constitucional que nos preocupa.

Si cuando el juez controla la constitucionalidad sustantiva de la ley debe examinar su contenido para examinar si se ajusta tanto a los parámetros de razonabilidad como proporcionalidad para evitar la arbitrariedad legislativa. Cuando analiza si existen vicios formales en la ley debe examinarla a la luz del principio de juridicidad para determinar si el órgano legislativo actuó fuera de su competencia o infringió las reglas procedimentales establecidas por la Carta, sin que le corresponda enjuiciar la legalidad de la actuación sino sólo su constitucionalidad.

\section{Contenido y comentario de la sentencia rol 2646 del Tribunal Constitucional, a la luz de los principios antes expuestos}

8.- Teniendo en cuenta los antecedentes y afirmaciones precedentes, estudiaremos ahora la sentencia del Tribunal Constitucional rol No 2646, de 22 de abril de 2014.

Sin embargo, antes de analizar su contenido preciso se hace necesario recordar las circunstancias especiales en que se presenta y se resuelve por el tribunal el requerimiento respectivo: se dedujo un día antes de que finalizara el mandato del Presidente Sebastián Piñera con el objeto de respaldar una actuación de éste, siendo examinado y resuelto por el tribunal estando ya en el cargo su sucesora, la Presidenta Michelle Bachelet.

El fallo resolvió el requerimiento de un grupo de senadores que solicitaron al Tribunal Constitucional resolver la inconstitucionalidad de la declaración de inadmisibilidad de 11 de las 28 observaciones formuladas por el entonces Jefe de Estado Sebastián Piñera, por vulnerar los arts. 72 y 73 de la Ley Fundamental. La acción se funda en que dichas observaciones se habrían enmarcado en el régimen de las ideas matrices establecido en el inciso $2^{\circ}$ del art. 73 , de manera que, con la referida actuación, se habría restringido indebidamente la facultad de vetar del Presidente de la República. Se pidió al tribunal dejar sin efecto dicha actuación solicitando, en subsidio, que se dejara sin efecto la declaración de inadmisibilidad de aquellas observaciones que, a juicio del tribunal, se ajustaran a la Carta.

En apoyo de sus argumentos, los actores esgrimen que el tribunal posee atribuciones para declarar la ilicitud de actuaciones legislativas desarrolladas durante la tramitación de un proyecto de ley, señalando que ello ocurrió en relación al fallo rol 2025, de 20 de julio de 2011, recaído en un requerimiento interpuesto durante la discusión del proyecto sobre permiso post parental; que las razones de mérito o conveniencia aducidas por el Presidente de la Cámara -en cuanto a que la declaración de inadmisibilidad era consecuencia de un acuerdo político adoptado por comisiones unidas de la Cámara- escapan a una motivación de carácter jurídico-constitucional; que la inadmisibilidad no puede constituir un rechazo político, porque la única limitación que tiene la admisibilidad del veto es que no viole las ideas matrices del proyecto; $y$, 
por último, que las observaciones declaradas inadmisibles no infringieron las ideas matrices del proyecto.

Luego de estimar que el requerimiento no podía prosperar porque no indicaba en forma precisa la norma impugnada del proyecto y de advertir que no ha acogido acciones dirigidas en contra de actuaciones sino sólo de preceptos legales (cons. $5^{\circ} \mathrm{a}$ $10^{\circ}$ ), el Tribunal Constitucional recuerda que la tramitación interna de los proyectos es materia de naturaleza legal según disposición de la propia Carta, correspondiéndole sólo resolver problemas de constitucionalidad y no de legalidad (cons. 140); que los acuerdos políticos son esenciales en la formación de la voluntad de los órganos colegiados, plurales y definidos por su naturaleza política, como son la Cámara de Diputados y el Senado, porque ellos facilitan el trabajo y permiten aunar voluntades (cons. $15^{\circ} \mathrm{a}$ 17a); que, en el caso, se llegó a un acuerdo en torno a votar ciertas observaciones y a declarar inadmisibles otras entre representantes del Ejecutivo y de todas las bancadas de la Cámara, sobre la base de una interpretación de buena fe y de prácticas de la corporación respecto de las facultades que el art. 32 de la ley orgánica No 18.918 otorga al Presidente de la Cámara para declarar inadmisible parcialmente el veto formulado por el Ejecutivo, sin que fuera reparado por el entonces Presidente de la República Sebastián Piñera vía requerimiento (cons. $19^{\circ}$ y $20^{\circ}$ ); que tal interpretación fue ratificada por el actual Ejecutivo (Michelle Bachelet), al evacuar el traslado al requerimiento, y por el Senado, pues éste no requirió como cuerpo colegiado sino sólo lo hizo un grupo de senadores, coincidiendo entonces los órganos colegisladores en el mismo criterio (cons. $21^{\circ}$ ); que el acuerdo posibilitó que se aprobara parte del veto, pues, de otro modo, éste no hubiera sido viable en su totalidad (cons. 220); que el tribunal debe considerar dicho acuerdo, "porque es parte común de la dinámica legislativa, permitió viabilizar el veto y se sustentó en una atribución de rango legal, no constitucional, en el marco de la autonomía que debe tener un órgano constitucional dotado de una particular legitimidad democrática, atendido el carácter electo de sus miembros, para lograr el éxito de ciertas iniciativas legales" (cons. 230); que si la existencia de un desacuerdo entre los órganos co-legisladores respecto de la conformidad de un determinado proyecto con la Carta Fundamental es de competencia del Tribunal Constitucional, en la hipótesis de autos tal desacuerdo no se produjo, por lo que no puede definir una contienda interpretativa que no germinó, ya que el Senado no hizo cuestión sobre el particular (cons. 24o); que respecto al fallo citado en el requerimiento -que declaró inconstitucional una norma del proyecto sobre creación del permiso postnatal parental por invadir atribuciones propias del Presidente de la República-, sostiene que esa situación era sustancialmente distinta al caso en especie, porque tal divergencia representó una infracción a la Carta y no una eventual vulneración legal, como ocurre en el caso (cons. 26); que el art. 32 de la ley orgánica del Congreso -que autoriza la declaración de inadmisibilidad del veto y fuera reformado para incluir la facultad de la sala para dirimir la procedencia o improcedencia de la inadmisibilidad ya declarada por el Presidente de la Cámara- es constitucional y "refuerza la soberania de la sala de la Cámara de origen"(cons. 29\%); que, citando jurisprudencia anterior, sostuvo que las "eventuales infracciones constitucionales 
durante el proceso legislativo deben considerar los principios de conservación o trascendencia y de economía del derecho", por lo que, cuando existen vicios de forma, el tribunal sólo declara inconstitucionales aquéllos que han influido decisivamente en el resultado y siempre que no hayan sido después corregidos durante la tramitación, y, en el caso, como las presuntas anomalías de la declaración de inadmisibilidad no fueron revocadas por la propia Cámara, precluyó la oportunidad procesal pertinente, quedando el tribunal inhibido para intervenir, ya que "una solución distinta implicaría inmiscuir a esta Magistratura en el debate legislativo y su mérito, función que no le es propia" (cons. $32^{\circ}$ ); que la impugnación se centra en la incompatibilidad entre el diseño de la ley 18.918 y la simetría del sistema constitucional, la que sólo quedaría resguardada si la segunda Cámara pudiera corregir el criterio de la originaria, no pudiendo el tribunal sustituirse a la segunda Cámara que, por soberana decisión del legislador orgánico, carece de injerencia en el asunto, lo cual además violaría los principios de corrección funcional y de conservación de los actos (cons. 33º).

Debido a las consideraciones anteriores, el Tribunal Constitucional rechazó el requerimiento en todas sus partes.

A su vez, el ministro Bertelsen concurrió al rechazo teniendo en cuenta que el momento y circunstancias en que fue presentado el requerimiento inciden en su examen y decisión, desde que éste se presentó cuando ni el Presidente de la Cámara ni el Jefe de Estado que gobernaba al momento de la actuación cuestionada pudieron ser oídos por el tribunal porque ya habían cesado en sus cargos, discrepando la actual Presidenta de la República con el veto antes formulado, por lo que, de prosperar la acción, ello obligaría a retrotraer la tramitación del veto al momento anterior a su conocimiento por parte de la Cámara, lo que permitiría a la actual Mandataria retirar el veto interpuesto por su antecesor, con lo cual la aceptación del requerimiento no tendría efecto práctico alguno.

Además de la prevención formulada por el ministro Vodanovic, el fallo contiene los votos en contra de los ministros Aróstica, Peña, Romero y Brahm, quienes sostuvieron que existía un problema de constitucionalidad que debía ser resuelto por el tribunal, basándose la controversia en una discrepancia entre órganos colegisladores en relación a la declaración de inadmisibilidad de las observaciones, incurriendo el Presidente de la Cámara en un vicio de constitucionalidad que afectó el proceso de formación de la ley, pues impidió que el contenido de todo el veto presidencial pudiera ser discutido, con lo que entendieron vulnerado el artículo 46 de la Carta, que prescribe que ambas Cámaras "concurren a la formación de las leyes en conformidad a esta Constitución".

9.- Ya hemos revisado someramente el principio de deferencia razonada a que deben ajustarse los órganos encargados de controlar la constitucionalidad de la ley y que se origina tanto en el postulado de la separación de las funciones públicas como, en especial, en la naturaleza y características que posee el Parlamento como órgano colegislador, dotado de autonomía no sólo para determinar, dentro del marco que le fija la Constitución, el contenido, oportunidad y mérito de la ley sino, también, para 
adoptar las decisiones de carácter político que crea necesarias dentro del proceso de debate y formación de la ley .

Como puede observarse del contenido del fallo del Tribunal Constitucional que acabamos de extractar, la mayoría de sus integrantes fue sumamente deferente con el Parlamento. En efecto, le otorgó valor y no cuestionó una declaración de inadmisibilidad basada en un acuerdo político adoptado en forma transversal entre distintos sectores con representación en la Cámara de Diputados y el Presidente de la República de la anterior administración en su carácter de colegislador. Este tipo de acuerdos constituye una práctica habitual en una democracia como la nuestra, mediante los cuales se intenta llegar a consenso entre los órganos colegisladores en torno a proyectos de ley que tienen trascendencia política y cuya aprobación se presenta como incierta.

El referido acuerdo buscó destrabar la tramitación legislativa del proyecto de televisión digital que llevaba mucho tiempo siendo debatido en el Congreso y que incluso ya había sido conocido por el propio Tribunal Constitucional al pronunciarse sobre un requerimiento anterior que declaró inconstitucional parte del mismo proyecto y constitucional la gran mayoría de sus preceptos, algunos de los cuales incluso fueron materia de las observaciones formuladas en el veto presidencial ${ }^{20}$.

La sentencia pone de relieve que al tribunal no le corresponde inmiscuirse en una actuación soberana del órgano legislativo, decidida en aplicación de una norma legal expresa, ni tampoco sustituirse a la apreciación a que podría haber llegado la Cámara revisora si hubiese conocido de la materia, reconociendo así la legitimidad de un acuerdo adoptado por órganos democráticamente elegidos, actuando en su rol de legisladores.

10.- Sin perjuicio de que compartimos el espíritu de la sentencia, debido a que da primacía a la autonomía política del Parlamento para decidir en una materia que le es propia y que dice relación con las prácticas que adopta para avanzar en la tramitación legislativa, nos parece que se sienta un precedente preocupante en relación al proceso de formación de la ley si es que no se reforma el art. 32 de la ley orgánica del Congreso que el Presidente de la Cámara aplicó para decidir la inadmisibilidad de algunas observaciones.

En efecto, frente a la presentación de un nuevo veto presidencial se podría ver alterado el quórum constitucional de los dos tercios de los miembros de cada Cámara para insistir con el proyecto aprobado por ellas si se mantiene la posibilidad de que se pueda declarar la inadmisibilidad de las observaciones por simple mayoría en una de las Cámaras y sin que la revisora tenga la oportunidad de pronunciarse sobre ellas.

Es decir, basta que una de las dos corporaciones declare su inadmisibilidad -fundada o infundadamente en relación a si las observaciones se ajustan o no a las ideas matrices o fundamentales del proyecto- para que la otra pierda toda opción de pronunciarse sobre el veto formulado. Esa posibilidad no parece guardar armonía ni con la letra ni

$20 \quad$ STC Rol N² 2541, de 18 de noviembre de 2013. 
con el espíritu de la Carta Fundamental, que atribuyó al veto una naturaleza diferente a la de constituir una mera indicación legislativa, lo que produciría un desbalance en desmedro del poder colegislador del Ejecutivo, que en nuestro actual sistema presidencial es sumamente hegemónico y vigorizado.

Lo que afirmamos es sin perjuicio, por cierto, de reconocer que, por las mismas características que presenta nuestro régimen gubernativo fuertemente presidencialista, convendría tal vez reformar la Carta Fundamental para lograr un mayor equilibrio entre el rol del Parlamento y el Primer Mandatario en el proceso de formación de la ley, destacando con mayor énfasis la relevancia que tiene el Parlamento en un sistema democrático representativo como el nuestro.

\section{Referencias Bibliográficas}

BÖCKENFORDE, ERnst Wolfgang (2000): Estudios sobre el Estado de Derecho y la democracia, Madrid, Editorial Trotta.

GARRORENA MORALES, Ángel (2011): Derecho Constitucional, Centro de Estudios Políticos y Constitucionales, Madrid.

HÄBERLE, Peter (2007): El Estado Constitucional, Ed. Astrea, Buenos Aires.

HELLER, Herman (1965): La soberanía, Editorial Universidad Autónoma de México, México.

SILVA BASCUÑÁN, Alejandro (1997): Tratado de Derecho Constitucional, Tomo I, Editorial Jurídica de Chile, Santiago.

SILVA G., María Pía (2013): "La potestad de autorregulación de las Cámaras y el control de constitucionalidad de sus reglamentos internos", en libro homenaje al profesor Alejandro Silva Bascuñán sobre Congreso Nacional, coordinado por Emilio Pfeffer Urquiaga, Ed. Jurídica de Chile, 2013.

ZAGREBELSKY, Gustavo (2005): El derecho dúctil, Ed. Trotta, Madrid.

ZAPATA LARRAÍN, Patricio (2008): Justicia Constitucional, Ed. Jurídica de Chile, Santiago.

\section{Jurisprudencia}

STC Rol No 2541, de 18 de noviembre de 2013.

STC Rol No 1295, de 6 de octubre de 2009.

STC Rol No 1295, de 6 de octubre de 2009.

STC Rol No 141, de 12 de febrero de 1992.

STC Rol No 334, de 21 de agosto de 2001. 
STC Rol No 43, de 24 de febrero de 1987.

STC Rol No 664, de 23 de noviembre de 2006.

STC Rol No 67, de 12 de mayo de 1989.

STC Rol No 797, de 24 de enero de 2008.

STC Rol No 811, de 31 de enero de 2008.

STC Rol N 549, de 24 de julio de 2006.

STC Rol No 1219, de 31 de enero de 2009. 